\title{
PELATIHAN SENI DAN MANAJEMEN SEKOLAH UNTUK PEMGIAT PENDIDIKAN MUHAMMADIYAH DI KOTA MADIUN
}

\author{
Oleh: Anang Masduki \\ Dosen Ilmu Komunikasi UAD \\ Email;anang.masduki@fsbk.uad.ac.id
}

\begin{abstract}
Ringkasan
Di era modern saat ini musik di indonesia berkembang sangat pesat. Hal ini dapat dikatakan dengan mempertimbangkan tingkat pasar dunia hiburan bidang musik yang kian ramai dan mahal. Namun dengan keadaan seperti ini perkembangan musik yang terjadi tidak diimbangi dengan nilai peningkatan kualitas dan estetika. UAD dengan program KKN mengadakan pelatihan penciptaan lagu islami, pembuatan dan musikalisasi puisi, festifal masjid dan juga pelatihan pembuatan cerpen. Kemudian akan diadakan lomba seni di tingkat masing-masing pendidikan dasar. Kemudian untuk menciptakan pendidikan yang unggul dan berkarakter agar mampu bersaing dengan institusi pendidikan yang lain maka diperlukan langkah-langkah seperti pelatihan manajemen sekolah dan branding sekolah. Pelatihan manajemen sekolah sangat penting mengingat dalam institusi pendidikan banyak sekali pekerjaan diluar mengajar yang harus diselesaikan. Disisi lain, persoalan citra sekolah yang belum bergengsi atau terstrandar internasional sangat mempengaruhi jumlah murid. Branding diperlukan untuk memperkuat citra dan menjaganya agar tumbuh dengan baik kepercayaan masyarakat.
\end{abstract}

Kata kunci: Manajemen, Branding, Festifal, Seni.

\begin{abstract}
In the current era of modern music in Indonesia is growing very rapidly. This can be said by considering the level of entertainment market world of music field that is increasingly crowded and expensive. But with these circumstances the development of music that occurs is not matched by the value of quality and aesthetic improvement. UAD with KKN program held training on creation of Islamic songs, making and musicalization of poetry, mosque festival and also training of short story making. Then there will be an art competition at each level of basic education. Then to create a superior education and character to be able to compete with other educational institutions it is necessary steps such as school management training and school branding. School management training is very important considering that in educational institutions there are so many unpaid work to do. On the other hand, the issue of school image that has not been prestigious or international standard greatly affects the number of students. Branding is needed to strengthen the image and keep it well-developed.
\end{abstract}

Keywords: Management, Branding, Festifal, Art.

\section{A. PENDAhuluan}

Dalam Muktamar Muhammadiyah di Makassar tahun 2015 lalu, diputuskan bahwa seni dan pendidikan sebagai salahsatu ranah dakwah Muhammadiyah yang perlu dikembangkan secara seriun. Oleh karenanya LSBO PP Muhammadiyah perlu menindaklanjutinya dengan tindakan kongkrit. Salahsatunya dengan mengadakan pekan seni mahasiswa Muhammadiyah. Kegiatan ini telah berjalan dengan maksimal dan sudah 
dilakukan beberapa kali dengan peserta seluruh PTM di Indonesia. (Berita Resmi Muhammadiyah, 2015: 46)

Adapun pekan seni pelajar mulai SD sampai SMA secara nasional belum terlaksana. Oleh karenannya UAD dengan program KKN akan mengadakan dengan berbasis wilayah karesidenan di Jawa khususnya. Untuk itu maka diperlukan penguatan skil untuk para pemangku pendidikan Muhammadiyah sebagai penunjang kegiatan tersebut. Salah satunya akan diadakan pelatihan penciptaan lagu islami, pembuatan dan musikalisasi puisi, festifal masjid dan juga pelatihan pembuatan cerpen. Kemudian akan diadakan lomba seni di tingkat masing-masing pendidikan dasar.

Kemudian untuk menciptakan pendidikan yang unggul dan berkarakter agar mampu bersaing dengan institusi pendidikan yang lain maka diperlukan langkah-langkah seperti pelatihan manajemen sekolah dan branding sekolah. Pelatihan manajemen sekolah sangat penting mengingat dalam institusi pendidikan banyak sekali pekerjaan diluar mengajar yang harus diselesaikan. Seperti pengelolaan dana BOS, penguatan karakter dengan integrasi ke pendidikan agama, hubungan masyarakat yang harus dijaga agar tetap baik serta kelengkapan fasilitas penunjang yang harus bagus dan nayaman.

Disisi lain, persoalan citra sekolah yang belum bergengsi atau terstrandar internasional sangat mempengaruhi jumlah murid. Branding diperlukan untuk memperkuat citra dan menjaganya agar tumbuh dengan baik kepercayaan masyarakat. Dengan kepercayaan yang baik maka jumlah murid yang selama ini menjadi permasalahan akan teratasi. Selain itu prestasi murid yang harus terus digenjot. Hal ini penting karena akan membuat branding semakin bagus. Dalam branding sekolah diperlukan upaya cermat untuk memanfaatkan setiap moment, selain prestasi juga penggunaan media sosial sangat penting untuk menyebarkan informasi yang positif. Seperti facebook, youtube, instagram maupun whatsup. Selain itu penggunaan media massa juga dirasa masih efektif.

Oleh karena itu UAD bekerjasama dengan PDM Kota Madiun akan mengadakan pelatihan seni, manajemen pendidikan dan branding sekolah.

\section{B. PEMBAHASAN}

1. Festival Masjid

Masjid berasal dari bahasa Arab sajada yang berarti tempat sujud atau tempat menyembah Allah swt. Umat Islam boleh melakukan shalat di wilayah mana pun di Bumi ini, kecuali di tempat-tempat yang menurut syariat Islam tidak layak untuk dijadikan tempat shalat, misalnya kuburan dan tempat-tempat najis. Selain itu, masjid juga menjadi tempat berkumpul dalam rangka meningkatkan solidaritas dan silaturrahmi di kalangan umat Islam.

Meminjam istilah Amien Rais, masjid-masjid dibagi menjadi tiga kelas, yakni Masjid Kelas 1, Masjid Kelas 2, dan Masjid Kelas 3.

a. Masjid Kelas 3 adalah masjid yang hanya digunakan sebagai tempat shalat dan pengurusnya cukup satu atau dua orang saja. Tugas pengurus masjid hanya membuka masjid waktu shalat, mengadzani dan mengiqamati, dan menjadi imam dalam shalat jamaah.

b. Masjid Kelas 2 adalah masjid seperti Masjid Kelas 3 namun di masjid ini dilaksanakan pula kegiatan taklim. 
Diterbitkan oleh Lembaga Pengabdian kepada Masyarakat

Universitas Ahmad Dahlan Yogyakarta

c. Masjid Kelas I adalah masjid Luas bangunan utama $10 \times 10 \mathrm{~m}$ atau lebih, dilengkapi dengan fasilitas dan sarana pendukung seperti tempat wudlu dan kamar mandi terpisah antara putera dan puteri, kamar takmir lengkap dengan kamar tidur, almari dan meja, gudang penyimpanan barang pecah belah dan sound system, tempat parkir kendaraan yang memadai, tempat penitipan sepatu/ sandal, perpustakaan lengkap dengan komputer, ruang-ruang untuk TPA, memiliki sarana olahraga, dan lain-lain.

Penilaian kriteria masjid.

1) Bidang I Eksistensi Masjid dan Aspek Pendukungnya

2) Bidang II Administrasi, Organisasi, dan Manajemen Masjid

3) Bidang III upaya memakmurkan masjid

4) Bidang IV sikap dan perhatian takmir masjid

2. Pelatihan Penciptaan Dan Pembelajaran Lagu Anak Sebagai Media Membangun

Karakter Karimah

Dengan melalui lembaga pendidikan bisa dijadikan sebagai alat untuk menyalurkan lagu-lagu yang cocok untuk diperdengarkan anak-ana yang diajarkan sejak tingkat Paud/TK, karena itulah masa-masa pertumbuhan masa emas. Lagu-lagu yang diajarkan sebaiknya lagu yang mengandung nilai islami yang mendidik. Seperti halnya yang dilakukan oleh Bapak Sigit Baskara. Beliau menekuni musik religi mulai dari tahun 2004. Semua berawal dari mengantar anaknya ke sekolah. Dengan pengalaman yang beliau miliki, beliau mejadi salah satu pemateri di acara pekan seni pelajar yang diadakan atas kerjasama mahasiswa KKN UAD, PDM se ekskarisidenan Madiun, dan ICM kota Madiun. Acar tersebut berlangsung lancar dengan antusias yang bagus dari para peserta yang ratarata merupakan pengajar TK dan SD.

Awal acara diisi dengan bagaimana bahayanya lagu-lagu sekarang yang kebanyakan memiliki tema dan pesan yang negatif dan bisa mempengaruhi akhlak penerus bangsa. Beliau banyak mencontohkan lagu-lagu yang sarat akan muatan negatif yang tidak sadar orang tua memperbolehkan anak mendengarkan lagu tersebut. Padahal efek yang ditimbulkan sangat mempengaruhi kehidupan anak kelak. Bukan hanyak lagu sekarang saja yang tidak disadari mempunyai nilai negatif, namun lagu anak-anak yang sering diperdengarkan di bangu taman kanak-kanak pun juga ada yang mempunyai nilai-nilai negatif. Lagu-lagu tersebut tanpa disadari selalu diajarkan kepada anak-anak yang masih polos dan belum mengerti arti lagu tersebut. Hal itu juga tidak disadari oleh para pengajar yang memberi lagu kepada anak tersebut. Maka dari itu para pengajar diminta untuk lebih teliti dalam mengajarkan dan lebih peka terhadaplagu tersebut.

\section{Pelatihan Mendongeng}

Kondisi pembelajaran bercerita di sekolah-sekolah di eks-Karesidenan Madiun beragam, ada yang malu, sedih, takut, segan, gembira, dan lain lain. Sehingga perlu adanya latihan yang tekun untuk benar-benar mampu menguasai cara pembelajaran bercerita yang dapat membantu anak dalam belajar.

Dalam proses berbahasa yang baik, terdapat empat keterampilan berbahasa yaitu: 
- Menyimak

- Berbicara

- Membaca

- Menulis

Dalam pelatihan ini, pemateri membagi peserta menjadi dua kelompok. Peserta diajak berfikir kreatif dan menggali inspirasi dengan cara membuat cerita bersambung. Cerita ini dirangkai dari satu kalimat oleh peserta satu dan dilanjutkan oleh peserta lainnya. Setelah giliran selesai, peserta terakhir harus memberi judul semenarik mungkin karena judul merupakan hal yang penting bagi pendongeng untuk mendapatkan perhatian audiens

Memperhatikan suara, artikulasi, jeda, dan ritme adalah hal yang penting dalam mendongeng. Untuk melatih artikulasi dan vokal sebaiknya pendongeng/guru sering berolahraga, menghirup udara pagi dan senam mulut. Selain itu, penting bagi pendongeng untuk menghindari makanan yang tidak sehat dan rokok.

Kesan pertama yang diberikan oleh pendongeng sangat penting diperhatikan. Hanya mengucapkan kalimat "Pada suatu hari" saja banyak sekali macamnya. Tergantung mana yang paling tepat digunakan. Hal ini dimaksudkan untuk membangun cerita semenarik mungkin dan mengkondisikan audiens.

Cara menyampaikan dongeng dapat dilakukan baik melalui media maupun tanpa media. Melalui media misalkan lewat boneka tangan, wayang gatel (gambar tempel), alatalat sederhana yang bisa dipakai, dan lain-lain. Sedangkan tanpa media bisa melalui mimik muka, dan bahasa tubuh sebaik-baiknya. Hal ini dilakukan agar memudahkan penyaluran cerita kepada audiens.

Dalam mempelajari cara mendongeng intinya adalah keterampilan berbahasa, pengembangan cerita, kreasi, dan orientasi bercerita. Sehingga peserta diharapkan mampu menguasai inti-inti tersebut agar dapat memberikan pembelajaran melalui bercerita dengan baik.

\section{Mengenal Puisi Melalui Musikalisasi Puisi}

Menurut pengertianya, musikalisasi sendiri diartikan sebagai Suatu kegiatan penciptaan musik berdasar sebuah puisi, sehingga pesan yang ada di puisi tersebut makin jelas maknanya. Selain itu, ada pula pemahaman dan pengertian lain dari musikalisasi tersebut yaitu mengekpresikan puisi dengan musik: Artinya musik hanya membantu puisi untuk lebih inovasi, agar pesan dalam puisi sampai kepada pendengar atau penikmat puisi tersebut.

Musikalisasi puisi sebenarnya sudah ada sejak tahun 1940-an. Dalam catatan sejarah musik Indonesia modern, tahun 1940-an awal Musikalisasi. Adalah komponis Cornel Simanjuntak bekerja sama dengan sastrawan Angkatan Pujangga Baru Sanusi Pane menghasilkan beberapa karya musik seriosa, antara lain: Kemuning, Oh Angin. Tetapi karena musikalisasi puisi kurang dikenal di Indonesia khususnya masyarakat awan yang lebih mengenal jenis music modern sampai saat ini musikalisasi puisi bisa dikatakan masih asing ditelingga masyarakat Indonesia pada umumnya.

Pada tahun 1960-an, pemusik FX Soetopo berkolaborasi dengan penyair Kirdjomulyo menghasilkan lagu-lagu Seriosa Puisi Rumah Bambu, Elegie dan lain lain. Juga sastrawan Taufiq Ismail ditahun 1970-an bekerja sama dengan grup musik Bimbo 
mencipta lagu lagu Pop Nasyid/rohani, menghasilkan antara lain Ada Anak Bertanya pada Bapaknya, Sajadah Panjang, Rindu Rosul dll. Mulai dari saat itu bias dikatakan musikalisasi puisi mulai terdengar namanya di masyarakat inndonesia.

Musikalisasi puisi berbeda dengan lagu-lagu yang dibawakan band. Musikalisasi puisi diciptakan dengan puisi yang sudah ada, sedangkan band diciptakan sejalan ketika menciptakn liriknya atau syairnya menyusul setelah nadanya ditentukan.

Tingkat kesulitan dalam menciptakan musikalisasi puisi lebih sulit atau rumet, penyesuai puisi dengan nada dalah bagian yang paling sulit dalam penciptaannya karena harus menyesuaikan puisi dengan tipografi yang tidak teratur dan kata yang cukup puitis. Selain itu, kesulitan juga terletak ketika mendapatkan puisi yang panjang.

Pada proses penciptaanya, penciptaan lagu pada sebuah Band yang diutamakan adalah nada atau instrumentnya, baru lirik lagunya menyusul secara bertahap. jika tidak, unsur liriknya disusun secara bertahap dahulu atau bisa dibilang sepatah dua patah kata dulu kemudian unsur nada atau instrument mengikutinya. Ternyata hal tersebut tidak sama dengan proses penciptaan musikalisasi puisi. Penciptaan musikalisasi itu sendiri, merupakan hal yang rumit. Penciptaan musikalisasi puisi: di awali dengan pemahaman suatu puisi yang telah tersedia atau yang telah ditentukan. Pemahama inilah yang akan menciptakan sebuah nada atau emosi dalam proses penciptaan.

Sebelum musik dialunkan, terlebih dahulu kita membedah suatu puisi yang ada. Dengan cara memparafrasekan dan makna puisi. Setelah makna dalam piusi tersebut dapat dipahami betul, baru setelah itu instrument musik dimainkan dengan menyesuaikan tema puisi yang telah tersedia.

Jika tema puisi tersebut bertema sosial biasanya musiknya lebih keras, jika tema puisinya romantis atau melo biasanya musiknya melo atau musik petik. Tergantung dengan jenis puisi yang diambil. Meskipn demikian penciptaan musikalisasi puisi tidak terbatas pada tema-tema yang ada. Pencipta berhak untuk menberikan atau memasukkan unsurunsur musik baik keras maupun melo yang menurut pencipta itu pas untuk dimasukkan. Tentu setelah paham dengan puisi terlebih dahulu.

5. Mengenal Pendidikan Muhammadiyah

Sekolah efektif adalah sekolah yang dapat dalam hal hasil, mencerminkan pembelajaran untu semua misi, menunjukan adanya ekuitas (Kewajaran) dalam kualitas atau Sekolah efektif adalah sekolah yang memiliki nilai tambah.

Karakteristik Sekolah Eektif

a. Kepemimpinan yang professional

b. Visi dan tujuan yang sama

c. Lingkungan belajar, jangan sampai kita menuntut anak didik bersih dan rapih sedangkan lingkungan sekolah kotor

d. Konsentrasi pada belajar mengajar, jangan sampai terjadi kesalah fahaman antara guru dan murid hanya karena cara penyampaian guru

e. Harapan yang tinggi

f. Penguatan/ pengayaan/pemantapan yang positif

g. Pemantauan kemajua

h. Hak dan kewajiban peserta didik 
i. Pengajaran yang penuh makna

j. Organisasi pembelajaran

k. Kemitraan keluarga sekolah

Kebanyakan sekolah mengikutsertakan wali murid hanya ketika waktu-waktu genting seperti pembagian raport, terkena kasus, dan meminta dana pembangunan.

Indikator Orang belajar yaitu bertambah pengetahuan, pengalaman, perubahan tingkah laku. Sekolah yang unggul itu bukan melahirkan siswa yang unggul dari bibit yang unggul tapi bagaimana sekolah mampu melahirkan siswa yang unggul dari bibit yang biasa saja sehingga tidak menganggap evaluasi sebagai satu-satunya ukuran pencapaian siswa.

Proses pendidikan intinya pada pembelajaran Input dan output: seringkali menyalahkan input padahal di tengah input dan output ada proses.

6. Branding sekolah

School branding adalah suatu pencitraan yg mampu mendiskripsikan secara general, positioning, dan keadaan dsuatu sekolah. Mencitrakan sekolah Melalui School branding memang harus diikuti pula dengan paket quality assurance.

\section{Teori Philip Kotler}

Disederhanakan oleh Hermawan Kertajaya dikenal:

- Positioning

- Diferensiation

- Brand

Positioning didukung diferensiasi yang kuat akan menghasilkan brand integrity, brand integrity kuat akan mengahsilkan brand identity /brand image. (Kotler, 2000:4)

Contoh: sabun lifeboy dan sabun lux.

\section{Brand}

- Marketing

- Logo

- Design

- Strategy

- Identity

- Advertising

1. Masalah kebutuhan pendidikan, maka jadikan sekolah solusi

- Masalah yang sangat urgent di dalam masyarakat saat ini, baik di sekolah, pemerintahan, keluarga atau di lingkunagan tempat tinggal kita

- Problem perkotaan

2. Tentukan kualitas lulusan yang ingin dihasilkan

- Hal ini sangat penting karena berkaitan dengan proses aktivitas di dalam kegiatan belajar, budaya sekolah dan brand sekolah itu sendiri

3. Buat nama brand yang menarik dan mudah di ingat usahakan dengan dua kata

- Sekolah kreatif (sudah banyak yang pake), creative school (sudah banyak yang pake juga), sekolah akhlak, sekolah alam, sekolah tangguh, sekolah cerdas, sekolah hebat, sekolah inspiratif, sekolah unggulan, sekolah hijau, sekolah karakter

- Kekuatan brand 
4. Membuat tim perancang implementasi brand sekolah ke dalam program

- Brand sekolah penghafal al-qur'an, maka setiap harinya skolah tersebut harus melakukan pembinaan hafalan al-qur' an

5. Tim pendidik jadilah teladan uatma dalam merealisasikan brand sekolah

- Saya sangat yakin sebuah brand sekolah hanya akan bisa berhasil jika ada keteladanan

6. Kampanyekan lewat media sosial (blog, twitter, facebook, dsb)

\section{Hasil penelitian Erik Qualman}

- Dibutuhkam waktu 38 tahun bagi radio untuk mencapai 50 juta pendengar

- Dibutuhkan waktu 13 tahun bagi televisi untuk mencapai 50 juta pemirsa

- Dibutuhkan waktu 4 tahun bagi internet untuk mencapai 50 juta netizen

- Sosial media facebook hanya butuh kurang dari 9 bulan sudah bisa 100 juta pengguna

\section{Akrab dengan soaial media}

- Pertama, agar ketika ada orang yang mencari informasi sekolah anda menjadi lebih mudah, sebisa mungkin buatlah akun sesuai dengan nama sekolah, semisal nama sekolah anda SMART Ekselensia Indonesia

- Kedua, buatlah jadwal untuk memposting informasi melalui akun yang anda miliki

- Ketiga, bangun keakraban dan interaksi dengan pengguna. Salah satu yang menarik dari sosial media adalah fitur like, share, coment ataupun retweet (Kompasiana 8 April 2014)

\section{Tugas}

1. Dibagi kelompok sesuai dengan sekolahnya masing-masing

2. Analisis permasalahan dan potensi yang bisa dikembangkan untuk karakter sekolah

3. Tentukan kualitas dan karakter yang ingin di bentuk

4. Buat brand nya

\section{Strategi menuju sekolah unggul}

- Tidak hanya menggunakan sistem hafalan

- Tidak hanya menjadikan Peserta didik sebagai objek

- Berfikir kretif dan inovatif

- Dimensi hubungan interaktif dan terbuka antara Guru dan Murid.

\section{KESIMPULAN}

Materi mendongeng disampaikan dalam untuk anak-anak dapat berasal dari nilainilai kehidupan sehari hari. Nilai-nilai sederhana perlu ditanamkan kepada anak sejak usia dini. Tiga hal sederhana yang dapat diajarkan kepada anak melalui mendongeng adalah : terimakasih, tolong, maaf. Hanya dari tiga hal tersebut saja akan memberi inspirasi yang beragam bagi guru untuk menyampaikan dongeng kepada anak didiknya.

Proses penciptaan Musuikalisasi puisi baru bisa terciptakan jika sudah tersedia sebuah puisi yang telah diciptakan terlebih dahulu oleh seorang pengarang. Setelah itu baru instrument musiknya menyusul. Musilaslsasi Puisi harus mengikuti keutuhan makna dari pemenggalan kata yang ada dalam puisi tersebut, karena dalam puisi pemenggalan kata akan merubah makna yang ada dalam puisi.

Bapak Sigit Baskara selaku pemateri juga memberi tips bagaimana menulis lagu dan membuat komposisi-komposisi nada dan tempo bahkan juga musik kepada para peserta 
pelatihan. Tips demi tips dijelaskan dengan rinci oleh beliau. Diakhir acara, beliau meminta para peserta menulis sebuah lirik lagu yang kemudian dinyanyikan didepan parahadirin. Semua itu dilakukan dengan tujuan praktek langsung agar para peserta lebih mengerti terhadap materi yang telah disampaikan. Bahkan ada salah satu karya dari peserta yang dipilih oleh Bapak Sigit Baskara karena karyanya disukai beliau. Itulah serentetan acara pelatiahn Cipta Lagu, semoga para pengajar lebih peka dan dapat memberikan lagu yang mendidik bagi para siswanya.

\section{DAFTAR PUSTAKA}

Kolter, Philip. Dkk, 2000. Manajemen Pemasaran dengan efektif dan Pofitable, cetakan kedua. Jakarta: Gramedia

Elfarizi Hakam, Sosial Media Sarana Membangun Brand Sekolah. Kompasiana 8 April 2014. Diakses 16 Agustus 2017

Mu'ti, Abdul, dkk. 2015. Berita Resmi Muhammadiyah, Tanfidz Keputusan Muktamar Makassar, Yogyakarta: PP Muhammadiyah 